Carlo Pozzilli, MD, PhD

Laura De Giglio, MD, $\mathrm{PhD}$

Valeria T. Barletta, MD

Fabiana Marinelli, MD

Floriana De Angelis, MD

Valentina Gallo, MD,

$\mathrm{PhD}$

Veronica A. Pagano, MSc

Stefano Marini, MSc

Maria C. Piattella, MD,

$\mathrm{PhD}$

Valentina Tomassini,

$\mathrm{MD}, \mathrm{PhD}$

Patrizia Pantano, MD

Correspondence to

Dr. Pozzilli:

carlo.pozzilli@uniroma1.it

Supplemental data at Neurology.org/nn

\section{Oral contraceptives combined with interferon $\beta$ in multiple sclerosis}

\section{OPEN}

\section{ABSTRACT}

Objective: To test the effect of oral contraceptives (OCs) in combination with interferon $\beta$ (IFN- $\beta$ ) on disease activity in patients with relapsing-remitting multiple sclerosis (RRMS).

Methods: One hundred fifty women with RRMS were randomized in a 1:1:1 ratio to receive IFN$\beta$-1a subcutaneously (SC) only (group 1), IFN- $\beta$-1a SC plus ethinylstradiol $20 \mu \mathrm{g}$ and desogestrel $150 \mu \mathrm{g}$ (group 2), or IFN- $\beta$-1a SC plus ethinylestradiol $40 \mu \mathrm{g}$ and desogestrel $125 \mu \mathrm{g}$ (group 3). The primary endpoint was the cumulative number of combined unique active (CUA) lesions on brain MRI at week 96. Secondary endpoints included MRI and clinical and safety measures.

Results: The estimated number of cumulative CUA lesions at week 96 was 0.98 (95\% confidence interval [Cl] 0.81-1.14) in group 1, $0.84(95 \% \mathrm{Cl} 0.66-1.02)$ in group 2, and $0.72(95 \% \mathrm{Cl}$ $0.53-0.91)$ in group 3 , with a decrease of $14.1 \%(p=0.24)$ and $26.5 \%(p=0.04)$ when comparing group 1 with groups 2 and 3, respectively. The number of patients with no gadoliniumenhancing lesions was greater in group 3 than in group $1(p=0.03)$. No significant differences were detected in other secondary endpoints. IFN- $\beta$ or OC discontinuations were equally distributed across groups.

Conclusions: Our results translate the observations derived from experimental models to patients, supporting the anti-inflammatory effects of OCs with high-dose estrogens, and suggest possible directions for future research.

Classification of evidence: This study provides Class II evidence that in women with RRMS, IFN- $\beta$ plus ethinylstradiol and desogestrel decreases the cumulative number of active brain MRI lesions compared with IFN- $\beta$ alone. Neurol Neuroimmunol Neuroinflamm 2015;2:e120; doi: 10.1212/ NXI.0000000000000120

\section{GLOSSARY}

$\mathbf{A E}=$ adverse event; $\mathbf{A R R}=$ annualized relapse rate; $\mathbf{C l}=$ confidence interval; $\mathbf{C U A}=$ combined unique active; $\mathbf{E A E}=$ experimental autoimmune encephalomyelitis; EDSS = Expanded Disability Status Scale; Gd = gadolinium; IFN = interferon; IL = interleukin; ITT = intention to treat; $\mathbf{M S}=$ multiple sclerosis; $\mathbf{O C}=$ oral contraceptive; RA = rheumatoid arthritis; RRMS = relapsing-remitting MS; SC = subcutaneous; tiw = 3 times a week.

Multiple sclerosis (MS) is an inflammatory disease with a higher prevalence in women, and it occurs at an average age that overlaps with their childbearing years. ${ }^{1,2}$

Interferon $\beta$ (IFN- $\beta$ ) is a widely used treatment for relapsing-remitting MS (RRMS) that is not associated with an increased risk of spontaneous abortion or fetal complications. ${ }^{3-6}$ However, to avoid unexpected pregnancies, clinicians are frequently asked about the risks of oral contraceptives (OCs) in combination with IFN- $\beta$ treatment. In the absence of practice guidelines, the use of OCs is discussed on an individual basis.

From the Department of Neurology and Psychiatry (C.P., L.D.G., F.D.A., M.C.P., V.T., P.P.), Sapienza University of Rome, Italy; MS Center (C.P., L.D.G., V.T.B., F.M.), S. Andrea Hospital, Sapienza University of Rome, Italy; Centre for Primary Care and Public Health (V.G.), Queen Mary University of London, UK; TFS Trial Form Support S.L. (V.A.P., S.M.), Rome, Italy; Institute of Psychological Medicine and Clinical Neurosciences (V.T.), Cardiff University School of Medicine University Hospital of Wales (V.T.), Cardiff, UK; Santa Lucia Foundation (V.T.), Rome, Italy; and IRCCS Neuromed (P.P.), Pozzilli (IS), Italy.

Coinvestigators are listed at Neurology.org/nn.

Funding information and disclosures are provided at the end of the article. Go to Neurology.org/nn for full disclosure forms. The Article Processing Charge was paid by Sapienza University of Rome, CIMS.

This is an open access article distributed under the terms of the Creative Commons Attribution-NonCommercial-NoDerivatives License 4.0 (CC BY-NC-ND), which permits downloading and sharing the work provided it is properly cited. The work cannot be changed in any way or used commercially. 
Although experimental evidence supports the anti-inflammatory properties of estrogens and treatment with high doses of the pregnancy hormone estriol has been demonstrated to ameliorate the course of $\mathrm{MS}^{7-9}$ whether OC use influences disease outcome is still a matter of debate. In patients using OCs, the onset of MS occurs at an older age ${ }^{10,11}$ and is associated with a less disabling course. ${ }^{12}$ On the other hand, in progressing-onset MS, a more rapid disease progression is associated with the use of OCs. ${ }^{13}$ Moreover, women receiving assisted reproduction technology treatment cycles showed a dramatic increase in MS disease activity, ${ }^{14}$ thus contributing to ambiguous evidence for the effect of sex hormones on MS.

This multicenter, randomized OC combination trial was designed to test the efficacy and safety of IFN- $\beta-1$ a subcutaneous (SC) combined with OCs on reducing disease activity in patients with RRMS. Based on clinical and experimental evidence, ${ }^{15}$ we hypothesized that estrogens exert anti-inflammatory effects in MS and these effects are dose-dependent.

METHODS Patients. Recruitment from 5 MS centers in Italy started in September 2004, and the last patient visit was in November 2009. Eligibility criteria included women with RRMS aged between 18 and 45 years, ${ }^{16}$ an Expanded Disability Status Scale (EDSS) score of $\leq 5.0$, at least 2 relapses in the previous 48 months or one relapse in the preceding 12 months, and no relapses or steroid intake in the previous 60 days. Exclusion criteria included pathology of the reproductive system, pregnancy or interruption of pregnancy in the previous 12 months, prior immunosuppressive therapy, use of IFN- $\beta$ or any experimental drugs before study entry, and use of glatiramer acetate and OCs in the prior 3 months.

Standard protocol approvals, registrations, and patient consents. This trial was registered with ClinicalTrials.gov (NCT00151801) and approved by the local ethics committees. Participants provided written informed consent.

Study design. This was a randomized, controlled, multicenter, investigator-run 24-month trial of combination therapy. After a screening phase, eligible patients were randomly assigned in a 1:1:1 ratio to receive IFN- $\beta$-1a $44 \mu \mathrm{g}$ (Rebif; Merck Serono, Geneva, Switzerland) 3 times a week (tiw) SC (group 1), IFN$\beta$-1a $44 \mu \mathrm{g}$ tiw SC plus ethinylestradiol $20 \mu \mathrm{g}$ and desogestrel $150 \mu \mathrm{g}$ (Mercilon; MSD Italia SRL, Rome, Italy) (group 2), or IFN- $\beta$-1a $44 \mu \mathrm{g}$ tiw SC plus ethinylestradiol $40 \mu \mathrm{g}$ and desogestrel $125 \mu \mathrm{g}$ (Gracial; Organon Italia S.p.A., Rome, Italy) (group 3). The randomization list was generated by a computer with a dynamic allocation by an independent national research organization (Istituto Superiore Sanità, Rome, Italy).

Study procedures. A 2-physician (treating and assessing) model was used to assist with study masking. The treating physician at each site was responsible for evaluating patient eligibility and for recording and managing adverse events (AEs). He or she was not blinded to treatment arm. The assessing physician was an independent and certified examining neurologist who was exclusively responsible for all neurologic assessments, beginning with the screening assessment and the EDSS scoring. He or she was blinded to treatment arm.

Clinical examinations were performed at baseline and then every 6 months. On-study relapse was defined as new or recurrent symptoms lasting for more than 24 hours and developing $\leq 30$ days after the onset of a previously confirmed exacerbation, in the absence of fever and with clinically objective changes on the neurologic examination. Relapses were treated with IV methylprednisolone $1 \mathrm{~g}$ daily for 3 to 5 consecutive days.

Safety measures included reports of AEs and clinical or laboratory test abnormalities. Interviews at follow-up visits focused on frequent symptoms attributed to OC use (e.g., migraine, smoking, hypertension, and deep vein thrombosis) and on adherence to the treatment. Laboratory tests were performed at screening, at baseline, every 4 weeks for the first 12 weeks, and then every 12 weeks.

Brain MRI scans were performed on $1.5 \mathrm{~T}$ systems at baseline, at week 48, and at week 96.

Standard MRI protocol was performed, consisting of 46 contiguous, $3 \mathrm{~mm}$-thick slices obtained in the axial plane before and 5 minutes after IV injection of $0.1 \mathrm{mmol} / \mathrm{kg}$ of gadolinium (Gd).

MRIs were sent electronically to the Neuroscience MRI Laboratory of Sapienza University of Rome for analysis. Hyperintense lesion volumes on T2-weighted images and hypointense lesion volumes on $\mathrm{T} 1$-weighted postcontrast images were identified and quantified using a semi-automated method (Jim 4.0; Xinapse Systems, Leicester, UK) requiring the agreement of 2 trained researchers (V.T.B. and M.C.P.) unaware of clinical data. When there was a disagreement, a third senior neuroradiologist reviewed the images and a final consensus was reached. On follow-up images, a lesion was defined as "new" if it did not overlap with a lesion seen on the previous images by more than $20 \%$ for small lesions (volume less than a sphere of $5 \mathrm{~mm}$ diameter) or $50 \%$ for larger lesions (volume greater than a sphere of 5 mm diameter).

Endpoints. The primary endpoint was the cumulative number of combined unique active (CUA) lesions at week 96, which were defined as new nonenhancing T2-weighted lesions or new Gdenhancing T1-weighted lesions (without double counting) (Class II evidence). Secondary MRI endpoints were the cumulative number of CUA lesions at week 48 , the mean number of new Gd-enhancing lesions per patient per scan at weeks 48 and 96, the percentage of patients with no Gdenhancing lesions at weeks 48 and 96, and the mean change from baseline in the total volume of T2-hyperintense lesions and T1-hypointense lesions at week 96 (Class II evidence).

Secondary clinical endpoints were the proportion of relapsefree patients and the proportion of patients with sustained disability progression, defined as a sustained increase (for 6 months) of at least 1 point in the EDSS score or an increase of at least 1.5 points if the baseline EDSS score was 0 (Class II evidence).

Safety measures. The safety assessments included clinical and laboratory-based AEs. Laboratory values 2.5-fold below or above normal limits were considered to be AEs and appropriate actions were taken. Tolerability was judged based on treatment discontinuations due to AEs.

Statistical analysis. This study was powered to detect an effect of OCs in combination with IFN- $\beta$ treatment on conventional 
MRI markers of inflammation. On the basis of previous data, ${ }^{17}$ the cumulative number of CUA lesions in group 1 at week 96 was estimated to be 2 , and the relative reduction in the number of CUA lesions was estimated to be $30 \%$ in group 3. Assuming $10 \%$ dropouts, 50 patients per group were required to provide a statistical power of $80 \%$ with a significance level of 0.05 .

The primary analyses were performed on the intention-totreat (ITT) population, which included all patients treated with at least 1 dose of IFN- $\beta$. To control for type I errors, multiplicity adjustment was applied to testing for comparisons between groups in a hierarchical order (first test: group 3 vs group 1; second test: group 2 vs group 1). Each test was performed at a significance level of 0.05 . The lower-rank testing was considered for inferential analysis only when higher-rank testing indicated statistical significance. The primary endpoint was calculated using a Poisson regression model with effect for study group and adjustment for age, baseline EDSS, and number of Gd-enhancing lesions. The cumulative number of CUA lesions at week 48 and the mean number of new Gd-enhancing lesions per patient per scan at weeks 48 and 96 were analyzed similarly to the primary endpoint. The percentage of patients with no Gd-enhancing lesions at weeks 48 and 96 was analyzed using a logistic regression model with effect for study group and adjustment for baseline number of Gd-enhancing lesions. Changes in the total volume of T2hyperintense lesions and T1-hypointense lesions at week 96 were measured by analysis of covariance with effect for study group and adjustment for baseline values. Annualized relapse rate (ARR) was measured by a negative binomial regression model with effect for study group and adjustment for age and number of relapses in the preceding 2 years. A Cox proportional hazards model was used to calculate the proportion of relapse-free patients and of patients with sustained progression at week 96, with adjustment for study group, age, and ARR in the former group and adjustment for baseline EDSS score in the latter group. Sensitivity analyses were conducted for an ITT-modified cohort, which consisted of all patients treated for at least 3 months. All statistical analyses were performed using SAS 9.1 (SAS Institute, Inc., Cary, NC).

Data management and analyses were performed by an independent research organization (TFS Trial Form Support S.L., Rome, Italy) with no role in the study design and data collection.

RESULTS Study population. A total of 192 women were considered eligible for the study. Forty-two declined to participate or were excluded in the screening phase, 150 were randomized, and 149 received at least 1 dose of the study drug (ITT population). Figure 1 shows patient allocation to the study groups.

A total of 148 patients completed the 96 weeks of follow-up. Five patients in group 1, 6 patients in group 2, and 4 patients in group 3 discontinued IFN- $\beta$ treatment. Twelve and 13 patients discontinued OCs prematurely in groups 2 and 3, respectively. Time at which treatment discontinuation occurred was comparable across groups. The mean (median) duration of IFN- $\beta$ therapy was 23.1 (24) months in group 1, 21.9 (24) months in group 2, and 23.8 (24) months in group 3 . The mean (median) duration of OC treatment was 20.6 (24) months in group 2 and 19.3 (24) months in group 3. Baseline characteristics were similar across the study groups (table 1).

\section{Figure 1 Numbers of patients who underwent randomization and completed 96 weeks of follow-up}

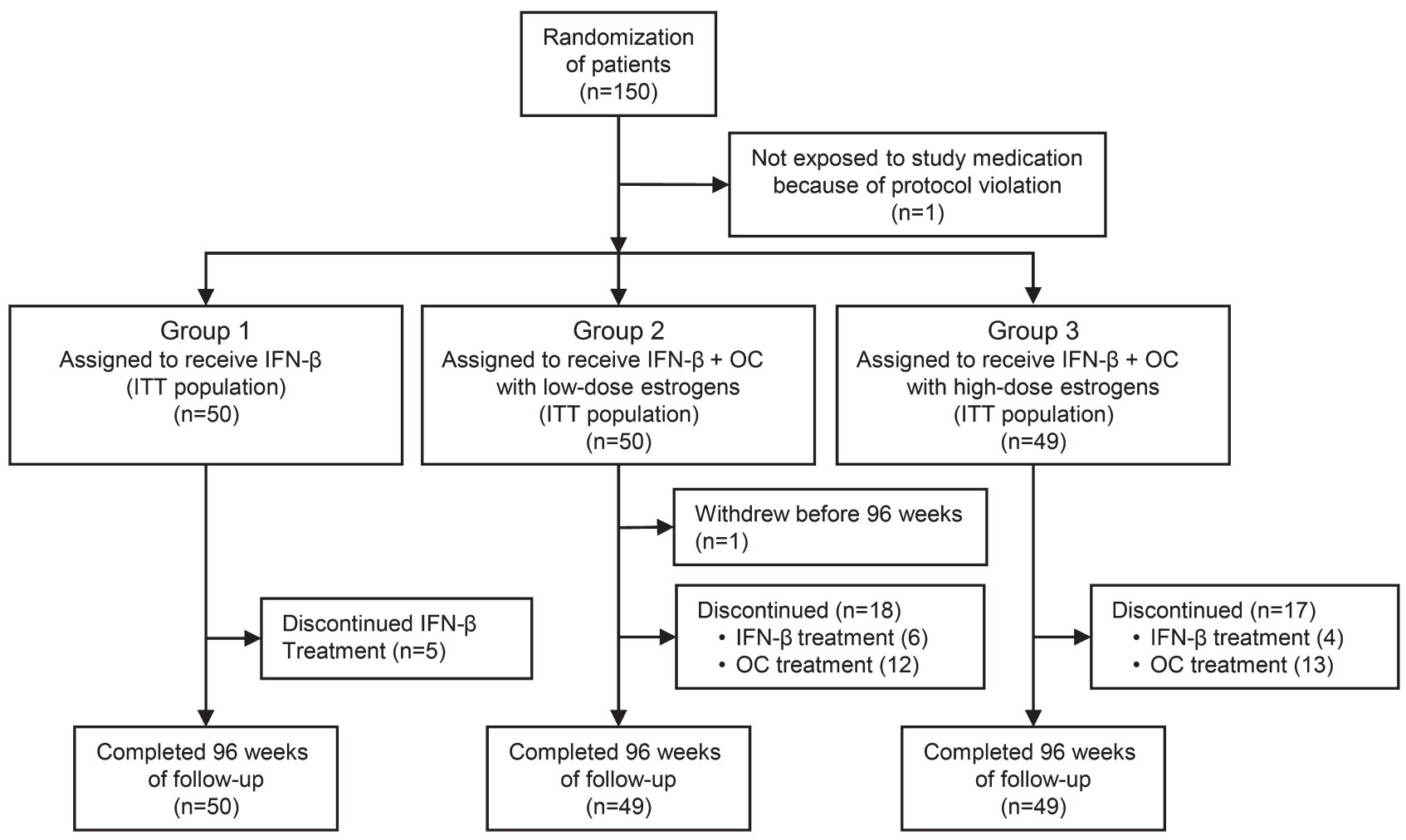

IFN = interferon; ITT $=$ intention to treat; $\mathrm{OC}=$ oral contraceptives. 
Table 1 Baseline demographic, disease, and MRI characteristics of the patients

\begin{tabular}{|c|c|c|c|}
\hline & $\begin{array}{l}\text { Group } 1 \\
(\mathrm{n}=50), \mathrm{IFN}-\beta\end{array}$ & $\begin{array}{l}\text { Group } 2(n=50) \text {, IFN- } \beta+\text { OC } \\
\text { with low-dose estrogens }\end{array}$ & $\begin{array}{l}\text { Group } 3(n=49) \text {, IFN- } \beta+\text { OC } \\
\text { with high-dose estrogens }\end{array}$ \\
\hline Age, y & $29.8 \pm 7.2$ & $28.9 \pm 6.8$ & $29.9 \pm 5.6$ \\
\hline Disease duration, y & $3.97 \pm 4.4$ & $3.41 \pm 3.2$ & $3.44 \pm 3.9$ \\
\hline $\begin{array}{l}\text { Annualized relapse rate in the } \\
\text { prior } 2 y\end{array}$ & $0.78 \pm 0.46$ & $0.74 \pm 0.34$ & $0.76 \pm 0.43$ \\
\hline $\begin{array}{l}\text { No. of women with previous } \\
\text { pregnancies }(\%)\end{array}$ & $11(22)$ & $8(16)$ & 9 (18) \\
\hline EDSS, median (range) & $1.5(0-4)$ & $1.5(0-4.5)$ & $1.5(0-5)$ \\
\hline Number of Gd-enhancing lesions & $1.7 \pm 1.9$ & $1.8 \pm 2.0$ & $1.6 \pm 1.9$ \\
\hline \multicolumn{4}{|l|}{$\begin{array}{l}\text { No. of patients with Gd-enhancing } \\
\text { lesions (\%) }\end{array}$} \\
\hline 0 & $21(42)$ & $18(36)$ & $20(41)$ \\
\hline More than 0 & $29(58)$ & $32(64)$ & $29(59)$ \\
\hline 1 & 8 & 13 & 13 \\
\hline 2 & 6 & 3 & 4 \\
\hline 3 & 2 & 2 & 3 \\
\hline$\geq 4$ & 13 & 14 & 9 \\
\hline $\begin{array}{l}\text { Volume of T2-hyperintense lesions, } \\
\mathrm{mm}^{3} \text {, median (range) }\end{array}$ & $6,514(649-32,724)$ & $5,933(762-61,428)$ & $5,655(992-51,928)$ \\
\hline $\begin{array}{l}\text { Volume of T1-hypointense lesions, } \\
\mathrm{mm}^{3} \text {, median (range) }\end{array}$ & $873(0-9,964)$ & $825(0-15,501)$ & $647(0-15,435)$ \\
\hline
\end{tabular}

Abbreviations: EDSS = Expanded Disability Status Scale; Gd = gadolinium; IFN = interferon; OC = oral contraceptive. The intention-to-treat population included all patients who underwent randomization and received at least 1 dose of IFN- $\beta$ treatment. None of the between-group comparisons were significant (nominal $p>0.05$ ). All values are expressed as mean $\pm S D$, unless otherwise indicated.

Efficacy. The estimated number of cumulative CUA lesions at week 96 (primary endpoint) was 0.98 (95\% confidence interval [CI] $0.81-1.14$ ) in group $1,0.84$ (95\% CI 0.66-1.02) in group 2, and 0.72 (95\% CI $0.53-0.91)$ in group 3 . This represented a relative reduction of $14.1 \%(p=0.24)$ for group 2 and $26.5 \%(p=0.04$ ) for group 3 (table 2; figure 2). Other MRI and clinical endpoints are also shown in table 2 .

Compared with group 1, group 3 showed a relative reduction of $65.4 \%$ in the number of new Gdenhancing lesions per patient per scan at week 48 $(p=0.04)$. At week 96 there was a trend for significance (relative reduction 54.2\%, $p=0.07$ ). Group 2 showed a nonsignificant relative reduction of $7.4 \%$ in the number of new Gd-enhancing lesions per patient per scan at week $48(p=0.83)$, with a trend to significance at week 96 (relative reduction $52.4 \%, p=$ 0.07) (figure e-1 at Neurology.org/nn).

A significant increase $(p=0.03)$ in the number of patients with no Gd-enhancing lesions at week 96 was observed in group 3 compared with group 1 (table 2).

No significant differences across groups were observed for the other MRI and clinical outcomes (table 2). No significant differences across groups were detected in the primary and secondary endpoints using the sensitivity analysis.
Finally, a significant correlation between CUA lesions at week 96 and baseline Gd-enhancing lesions was found in group 1 but not in groups 2 and 3, as shown in figure e-2.

Safety. All patients followed the prescribed regimen of the IFN- $\beta$ treatment. Fifteen patients withdrew from IFN- $\beta$ treatment. Reasons for IFN- $\beta$ withdrawal were AEs $(n=5)$, disease progression $(n=7)$, lost to follow-up $(n=2)$, and pregnancy $(n=1)$.

The incidence of IFN- $\beta$-related AEs was similar in the 3 groups, except for a slightly lower incidence of flu-like syndrome in the OC-treated groups than in group 1 (table e-1). There were no serious AEs. AEs were of mild or moderate severity in the majority of patients. OC-related AEs occurred similarly in the 2 OC groups. Only 1 patient in group 2 interrupted OC treatment following an episode of deep vein thrombosis (table e-1).

DISCUSSION Our study showed that the antiinflammatory effect of treatment, as measured by MRI activity, was more pronounced in patients receiving high-dose estrogens than in those receiving IFN- $\beta$ alone. Although the study was not powered to demonstrate a significant reduction in the relapse rate or in the proportion of patients with sustained disability progression, we investigated 


\begin{tabular}{|c|c|c|c|c|c|}
\hline & $\begin{array}{l}\text { Group 1 } \\
(n=50), \text { IFN- } \beta\end{array}$ & $\begin{array}{l}\text { Group } 2(n=50) \text {, IFN- } \beta+\text { OC } \\
\text { with low-dose estrogens }\end{array}$ & $\begin{array}{l}\text { Group } 3(n=49) \text {, IFN- } \beta+O C \\
\text { with high-dose estrogens }\end{array}$ & $\begin{array}{l}p \text { Value, } \\
\text { group } 2 \text { vs } \\
\text { group } 1\end{array}$ & $\begin{array}{l}p \text { Value, } \\
\text { group } 3 \text { vs } \\
\text { group } 1\end{array}$ \\
\hline $\begin{array}{l}\text { Cumulative no. of CUA lesions at week } 96 \\
(95 \% \mathrm{Cl}) \text {; relative reduction, \% }\end{array}$ & $0.98(0.81-1.14)$ & 0.84 (0.66-1.02); 14.1 & $0.72(0.53-0.91) ; 26.5$ & $0.24^{a}$ & $0.04^{a}$ \\
\hline $\begin{array}{l}\text { Cumulative no. of CUA lesions per patient } \\
\text { per scan at week } 48(95 \% \mathrm{Cl}) \text {; relative } \\
\text { reduction, \% }\end{array}$ & $0.39(0.17-0.62)$ & $0.42(0.19-0.64) ;-5.8$ & $0.33(0.10-0.56) ; 16.0$ & $0.88^{a}$ & $0.69^{a}$ \\
\hline $\begin{array}{l}\text { No. of new Gd-enhancing lesions per patient } \\
\text { per scan at week } 96(95 \% \mathrm{Cl}) \text {; relative } \\
\text { reduction, \% }\end{array}$ & $0.24(0.13-0.43)$ & $0.11(0.05-0.24) ; 52.4$ & $0.11(0.05-0.24) ; 54.2$ & $0.07^{a}$ & $0.07^{a}$ \\
\hline $\begin{array}{l}\text { Patients with no Gd-enhancing lesions at } \\
\text { week } 48, n(\%)\end{array}$ & $41(82)$ & $38(76)$ & 45 (92) & $0.98^{b}$ & $0.11^{\mathrm{b}}$ \\
\hline $\begin{array}{l}\text { Reduction of T1-hypointense volume over } \\
96 \mathrm{wk} \text {, mean } \pm \text { SD }\end{array}$ & $11.10 \pm 55.05$ & $18.00 \pm 53.52$ & $4.88 \pm 48.37$ & $0.35^{\mathrm{c}}$ & $0.98^{c}$ \\
\hline $\begin{array}{l}\text { Annualized relapse rate from week } 0 \text { to } \\
\text { week } 96 \text {, mean } \pm S D\end{array}$ & $0.33 \pm 0.08$ & $0.44 \pm 0.09$ & $0.32 \pm 0.08$ & $0.34^{d}$ & $0.97^{d}$ \\
\hline $\begin{array}{l}\text { Patients relapse-free from week 0-96, n (\%); } \\
\text { hazard ratio with group } 1(95 \% \mathrm{Cl})\end{array}$ & $17(34.0)$ & 23 (46.0); 1.51 (0.81-2.85) & 16 (32.7); 0.98 (0.49-1.94) & $0.20^{e}$ & $0.95^{\mathrm{e}}$ \\
\hline $\begin{array}{l}\text { Patients relapse-free from week 0-48, } \\
\text { n (\%); hazard ratio with group } 1(95 \% \mathrm{Cl})\end{array}$ & $38(76.0)$ & 28 (56.0); 1.65 (0.80-3.41) & 39 (79.6); 0.95 (0.42-2.16) & $0.17^{f}$ & $0.90^{f}$ \\
\hline $\begin{array}{l}\text { Patients relapse-free from week } 48-96 \text {, } \\
\text { n (\%); hazard ratio with group } 1(95 \% \mathrm{Cl})\end{array}$ & 39 (78.0) & 38 (76.0); 1.155 (0.49-2.68) & 42 (85.7); 0.75 (0.30-1.875) & $0.538^{f}$ & $0.738^{f}$ \\
\hline $\begin{array}{l}\text { Patients with sustained disability progression } \\
\text { at week } 96, \mathrm{n}(\%) \text {; hazard ratio with group } \\
1(95 \% \mathrm{Cl})\end{array}$ & $3(6)$ & $6(12) ; 1.36(0.72-2.58)$ & 4 (8); 0.97 (0.49-1.92) & $0.348^{f}$ & $0.927^{f}$ \\
\hline
\end{tabular}

Abbreviations: $\mathrm{Cl}$ = confidence interval; $\mathrm{CUA}=$ combined unique active; EDSS = Expanded Disability Status Scale; Gd = gadolinium; IFN = interferon; $\mathrm{OC}=$ oral contraceptive.

${ }^{a}$ Calculated using a Poisson regression model with adjustment for study group, age, number of Gd-enhancing lesions, and EDSS at baseline.

${ }^{b}$ Calculated using a logistic regression model with adjustment for study group and baseline number of Gd-enhancing lesions.

${ }^{\mathrm{c}}$ Calculated using analysis of covariance on ranks with adjustment for study group.

${ }^{d}$ Calculated using negative binomial regression model with effect for study group and adjustment for age and number of relapses in the previous 2 years.

${ }^{e}$ Calculated using Cox proportional hazards model with adjustment for study group, age, and annualized relapse rate before study entry.

${ }^{f}$ Calculated using Cox proportional hazards model with adjustment for study group, age, and EDSS score at baseline.

these endpoints and found that treatment with highdose estrogens was not associated with reduction. However, it must be emphasized that the population studied was young women and very few patients $(>20 \%)$ showed a progression sustained for 6 months during the 2-year study. The combination was well-tolerated and common AEs were generally equally distributed across treatment groups.

As with other exploratory MS trials targeting inflammatory processes, changes in MRI markers of inflammation were selected as the first indication of a potential therapeutic effect. MRI activity is as an accepted surrogate outcome measure in proof-ofconcept clinical trials, and changes in CUA lesions are the primary targets in relapse-onset MS studies. ${ }^{18}$

Several studies using the experimental autoimmune encephalomyelitis (EAE) model suggest an anti-inflammatory effect of estradiol, providing disease protection in several strains of mice. ${ }^{7}$ This anti-inflammatory effect of estradiol is mediated by nuclear estrogen receptor alpha and involves a variety of mechanisms, including the induction of $\mathrm{CD} 4{ }^{+} \mathrm{CD} 25^{+}$regulatory $\mathrm{T}$ cells and favorable changes in autoantigen-specific cytokine production in the peripheral immune system (i.e., decreased tumor necrosis factor $\alpha$, IFN- $\gamma$, and interleukin [IL]-6, with increased IL-5). ${ }^{19,20}$ It has been suggested that the levels of estrogens in OC formulations are not high enough to play an anti-inflammatory role in MS. However, patients receiving OCs are less likely to experience worsening of MS symptoms during the menstrual cycle. ${ }^{21}$ Studies simulating treatment with oral estradiol in EAE have shown a beneficial effect of this hormone, suggesting that sustained levels of estradiol are necessary to reduce disease activity. ${ }^{22,23}$ Progesterone, another component of OCs, also has 
Figure 2 Primary endpoint: Cumulative number of combined unique active (CUA) lesions at week 96

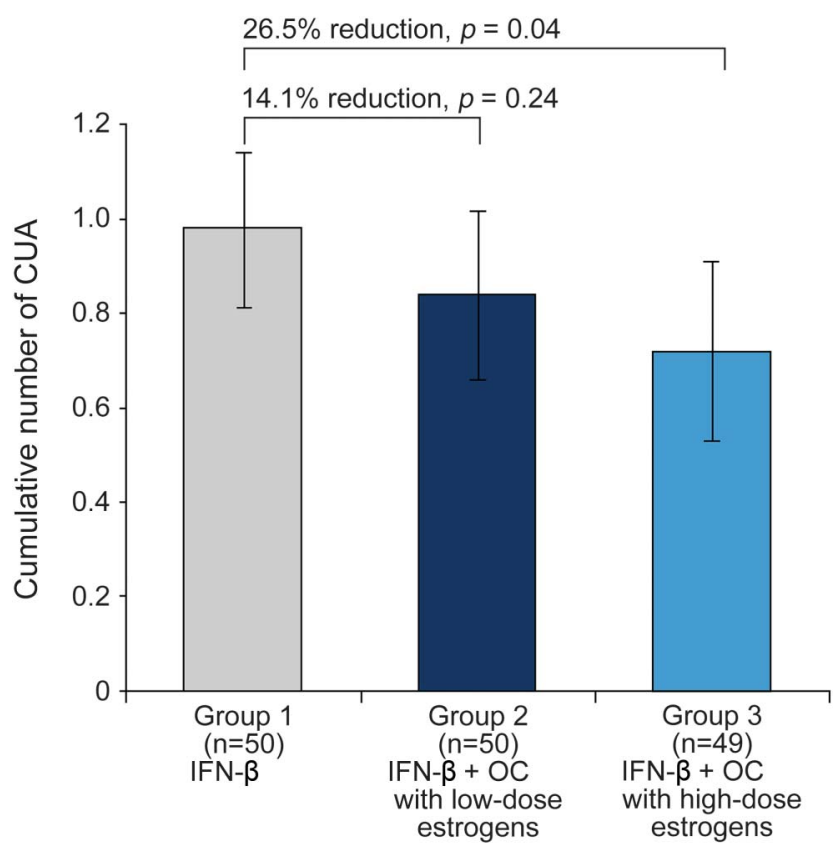

The primary endpoint was calculated using a Poisson regression model adjusted for study group, age, baseline Expanded Disability Status Scale score, and number of gadoliniumenhancing lesions. Values are expressed as estimated number per patient; error bars represent $95 \%$ confidence interval. IFN $=$ interferon beta; $\mathrm{OC}=$ oral contraceptives.

immunomodulatory effects. Although its beneficial effect in $\mathrm{EAE}$ is controversial, ${ }^{7}$ its combination with estradiol has been shown to influence disease activity in MS. ${ }^{24,25}$ The ratio of progesterone to estradiol during the luteal phase was significantly associated with Gd-enhancing lesion burden. ${ }^{25}$

A dose effect of OCs was apparent in this study, as reflected by a temporal delay of anti-inflammatory action in the low estrogen group compared with the high-dose group. OCs with high-dose estrogens suppressed MRI activity in the first year, whereas OCs with low-dose estrogens demonstrated a favorable effect only in the second year of treatment (see table 2). Studies on disease activity in rheumatoid arthritis (RA) have provided further clues with respect to which doses of estrogens are potentially protective in MS. In a randomized placebo-controlled trial of estradiol in RA, patients who achieved a serum estradiol level $>100 \mathrm{pmol} / \mathrm{L}$ experienced significant improvements in symptoms and disease markers, whereas those with lower levels of estradiol did not. ${ }^{26}$ Together these reports suggest that estradiol concentration and duration of exposure may exert different effects on receptors or target immune cells, with a varying degree of biological relevance. Safety consideration limited the dose of estrogen contained in the OC used in the present trial. Moreover, the 2 arms of OC treatment contained not only different doses of estrogen but also slightly different doses of progestrel; thus, the possibility of a combined effect cannot be ruled out.

Whether OCs with high-dose estrogens enhance the effect of IFN- $\beta$ or IFN- $\beta$ predisposes the immune system to the beneficial effects of OCs remains uncertain. The beneficial effect of high-dose estrogens on MRI activity in this study could be mediated by an inhibition of neutralizing antibodies to IFN- $\beta$ resulting from the immunomodulatory effects of estrogens. This hypothesis cannot be ruled out since IFN- $\beta$-neutralizing antibodies were not tested in the present study. On the other hand, IFN- $\beta$ treatment administered in combination with hormone therapy may also modify the responsiveness of hormone receptors for estrogen..$^{27,28}$

Although high-dose estrogens in combination with IFN- $\beta$ show a beneficial effect, the risk-benefit ratio of estrogen treatment requires some consideration. OC treatment is a well-recognized risk factor for vascular disorders. In this study, the rate of OC treatment discontinuation due to AEs was similar in the groups treated with high- and low-dose estrogens. One patient treated with low-dose estrogens prematurely interrupted treatment because of an episode of deep venous thrombosis. Although some evidence suggests a possible increase in venous thromboembolism with OCs containing $>35 \mu \mathrm{g}$ ethinylestradiol, robust data to support this conclusion are lacking. ${ }^{29}$

The rate of IFN- $\beta$ discontinuation was similar in the OC-treated groups and the group treated with IFN- $\beta$ alone. The incidence of common IFN- $\beta$ related AEs was also similar across the groups, although flu-like symptoms appeared slightly less frequently in the OC-treated groups. Whether OCs played a role in attenuating the development of flulike symptoms through their immunomodulatory properties remains unclear. However, this observation must be interpreted with caution since treating physicians were not blinded to treatment arms.

Overall, the results of this study suggest that the use of high-dose estrogens in combination with IFN- $\beta$ increases the anti-inflammatory effect of IFN- $\beta$ treatment in RRMS, possibly through additive or synergistic effects, and it is well-tolerated by patients. Further studies will be necessary to prove a sustained, clinically meaningful anti-inflammatory effect of hormone-based therapy in MS. Extending the investigations on the use of estrogen-based compounds to aspects of tissue protection and repair will allow their full potential to be realized in MS treatment.

\section{AUTHOR CONTRIBUTIONS}

C.P. is the principal investigator of the study. He designed and supervised the study, was responsible for recruitment and data analysis, and drafted the manuscript. He acted as guarantor for the accuracy and honesty of 
the report and the morality of the study. L.D.G. coordinated the study procedures, acted as treating physician of the study. and contributed to writing the manuscript. V.T.B. and M.C.P. performed the MRI data collection and analysis. F.M. and F.D.E. acted as assessing physicians. V.A.P. and S.M. undertook the statistical plan and the data analysis. V.G. was responsible for randomization and data acquisition and contributed to the discussion of results. V.T. generated the hypotheses of the study and designed the study with C.P. She performed the neurologic assessments and contributed to the discussion of the results and the writing of the manuscript. P.P. supervised MRI data collection and analysis and contributed to the discussion of the results and the revision of the manuscript.

\section{ACKNOWLEDGMENT}

The authors thank Bruce Bebo, Associate Vice-President for Discovery Research at the National MS Society, for useful discussion on the interpretation of the results.

\section{STUDY FUNDING}

The study was supported by the following grants: Ateneo and Facoltà, Sapienza University of Rome 2005-2011; and Federazione Italiana Sclerosi Multipla FISM 2007.

\section{DISCLOSURE}

C. Pozzilli has served on the scientific advisory boards of Novartis, Merck Serono, Biogen Idec, Sanofi-Aventis, Teva Neuroscience, and Bayer; has received funding for travel and speaker honoraria from Sanofi-Aventis, Biogen Idec, Bayer, Teva Neurosciences, Merck Serono, and Novartis; and is receiving research support from Biogen Idec, Merck Serono, Bayer, and Novartis. L. De Giglio, V.T. Barletta, F. Marinelli, and F. De Angelis report no disclosures. V. Gallo is an editor for Conference Papers in Medicine, World Journal of Neurology, Dataset Papers in Medicine, World Journal of Meta-Analysis, Clinical Epidemiology Reviews, and International Journal of Neurology Research. V.A. Pagano, S. Marini, and M.C. Piattella report no disclosures. V. Tomassini has served on the scientific advisory board of Biogen Idec and received research support from the Italian Ministry of Health, MS Society Italy, MS Society UK, MS International Federation, and Cardiff University Funds. P. Pantano received speaker honoraria from Biogen. Go to Neurology.org/nn for full disclosure forms.

Received August 28, 2014. Accepted in final form May 4, 2015.

\section{REFERENCES}

1. Compston A, Coles A. Multiple sclerosis. Lancet 2008; 372:1502-1517.

2. Ascherio A, Munger K. Epidemiology of multiple sclerosis: from risk factors to prevention. Semin Neurol 2008;28: 17-28.

3. IFNB Multiple Sclerosis Study Group. Interferon beta-1b is effective in relapsing-remitting multiple sclerosis. I. Clinical results of a multicenter, randomized, doubleblind, placebo-controlled trial. Neurology 1993;43: 655-661.

4. Jacobs LD, Cookfair DL, Rudick RA, et al. Intramuscular interferon beta-1a for disease progression in relapsing multiple sclerosis. Ann Neurol 1996;39:285-294.

5. PRISMS Study Group. Randomised double-blind placebocontrolled study of interferon beta-1a in relapsing/remitting multiple sclerosis. Lancet 1998;352:1498-1504.

6. Amato MP, Portaccio E, Ghezzi A, et al. Pregnancy and fetal outcomes after interferon- $\beta$ exposure in multiple sclerosis. Neurology 2010;75:1794-1802.

7. Voskuhl R, Palazynski K. Sex hormones in experimental autoimmune encephalomyelitis: implications for multiple sclerosis. Neuroscientist 2001;7:258-270.
8. Tomassini V, Pozzilli C. Sex hormone, brain damage and clinical course of MS. J Neurol Sci 2009;286:35-39.

9. Sicotte NL, Liva SM, Klutch R, et al. Treatment of multiple sclerosis with the pregnancy hormone estriol. Ann Neurol 2002;52:421-428.

10. Alonso A, Clark CJ. Oral contraceptives and the risk of multiple sclerosis: a review of the epidemiologic evidence. J Neurol Sci 2009;286:73-75.

11. Holmqvist P, Hammar M, Landtblom AM, Brynhildsen J. Age at onset of multiple sclerosis is correlated to use of combined oral contraceptives and childbirth before diagnosis. Fertil Steril 2010;94:2835-2837.

12. Sena A, Couderc R, Vasconcelos JC, Ferret-Sena V, Pedrosa RJ. Oral contraceptive use and clinical outcomes in patients with multiple sclerosis. J Neurol Sci 2012;317: 47-51.

13. D'hooghe MB, Haentjens P, Nagels G, D'Hooghe T, De Keyser J. Menarche, oral contraceptives, pregnancy and progression of disability in relapsing onset and progressive onset multiple sclerosis. J Neurol 2012;259:855-861.

14. Correale J, Farez MF, Ysrraelit MC. Increase in multiple sclerosis activity after assisted reproduction technology. Ann Neurol 2012;72:682-694.

15. Tomassini V, Pozzilli C. Sex hormones: a role in the control of multiple sclerosis. Expert Opin Pharmacother 2006; 7:857-868.

16. McDonald WI, Compston A, Edan G, et al. Recommended diagnostic criteria for multiple sclerosis: guidelines from the International Panel on the diagnosis of multiple sclerosis. Ann Neurol 2001;50:121-127.

17. PRISMS Study Group, University of British Columbia MS/MRI Analysis Group. PRISMS-4: Long-term efficacy of interferon-beta-1a in relapsing MS. Neurology 2001;56: 1628-1636.

18. Barkhof F, Simon JH, Fazekas F, et al. MRI monitoring of immunomodulation in relapse-onset multiple sclerosis trials. Nat Rev Neurol 2011;8:13-21.

19. Morales LB, Loo KK, Liu HB, Peterson C, TiwariWoodruff S, Voskuhl RR. Treatment with an estrogen receptor alpha ligand is neuroprotective in experimental autoimmune encephalomyelitis. J Neurosci 2006;26:6823-6833.

20. Matejuk A, Bakke AC, Hopke C, Dwyer J, Vandenbark AA, Offner H. Estrogen treatment induces a novel population of regulatory cells, which suppresses experimental autoimmune encephalomyelitis. J Neurosci Res 2004;77:119-126.

21. Zorgdrager A, De Keyser J. Menstrually related worsening of symptoms in multiple sclerosis. J Neurol Sci 1997;149: 95-97.

22. Bebo BF Jr, Fyfe-Johnson A, Adlard K, Beam AG, Vandenbark AA, Offner H. Low-dose estrogen therapy ameliorates experimental autoimmune encephalomyelitis in two different inbred mouse strains. J Immunol 2001; 166:2080-2089.

23. Subramanian S, Matejuk A, Zamora A, Vandenbark AA, Offner H. Oral feeding with ethinyl estradiol suppresses and treats experimental autoimmune encephalomyelitis in SJL mice and inhibits the recruitment of inflammatory cells into the central nervous system. J Immunol 2003; 170:1548-1555.

24. Bansil S, Lee HJ, Jindal S, Holtz CR, Cook SD. Correlation between sex hormones and magnetic resonance imaging lesions in multiple sclerosis. Acta Neurol Scand 1999; 99:91-94. 
25. Pozzilli C, Falaschi P, Mainero C, et al. MRI in multiple sclerosis during the menstrual cycle: relationship with sex hormone patterns. Neurology 1999;53:622-624.

26. Hall GM, Daniels M, Huskisson EC, Spector TD. A randomised controlled trial of the effect of hormone replacement therapy on disease activity in postmenopausal rheumatoid arthritis. Ann Rheum Dis 1994;53: 112-116.

27. De Cicco Nardone F, Rossiello F, Iacopino F, et al. Effects of interferon-beta on steroid receptors, prostaglandins and enzymatic activities in human endometrial cancer. Anticancer Res 1996;16:161-169.

28. Barak V, Kalickman I, Nisman B, et al. Changes in cytokine production of breast cancer patients treated with interferons. Cytokine 1998;10:977-983.

29. Reid R; Society of Obstetrician and Gynaecologists of Canada. SOGC clinical practice guideline. No. 252, December 2010. Oral contraceptives and the risk of venous thromboembolism: an update. J Obstet Gynaecol Can 2010;32:1192-1204. 


\section{Neurology \\ Neuroimmunology \& Neuroinflammation}

Oral contraceptives combined with interferon $\beta$ in multiple sclerosis

Carlo Pozzilli, Laura De Giglio, Valeria T. Barletta, et al.

Neurol Neuroimmunol Neuroinflamm 2015;2;

DOI 10.1212/NXI.0000000000000120

This information is current as of June 18, 2015

Updated Information \&

Services

Supplementary Material

References

Subspecialty Collections

Permissions \& Licensing

Reprints including high resolution figures, can be found at:

http://nn.neurology.org/content/2/4/e120.full.html

Supplementary material can be found at:

http://nn.neurology.org/content/suppl/2015/06/18/2.4.e120.DC1

http://nn.neurology.org/content/suppl/2015/06/18/2.4.e120.DC2

This article cites 29 articles, 4 of which you can access for free at: http://nn.neurology.org/content/2/4/e120.full.html\#\#ref-list-1

This article, along with others on similar topics, appears in the following collection(s):

Class II

http://nn.neurology.org//cgi/collection/class_ii

Clinical trials Randomized controlled (CŌNSORT agreement)

http://nn.neurology.org//cgi/collection/clinical_trials_randomized_cont rolled_consort_agreement

Multiple sclerosis

http://nn.neurology.org//cgi/collection/multiple_sclerosis

Information about reproducing this article in parts (figures,tables) or in its entirety can be found online at:

http://nn.neurology.org/misc/about.xhtml\#permissions

Information about ordering reprints can be found online:

http://nn.neurology.org/misc/addir.xhtml\#reprintsus

Neurol Neuroimmunol Neuroinflamm is an official journal of the American Academy of Neurology.

Published since April 2014, it is an open-access, online-only, continuous publication journal. Copyright $\odot$ 2015 American Academy of Neurology. All rights reserved. Online ISSN: 2332-7812.

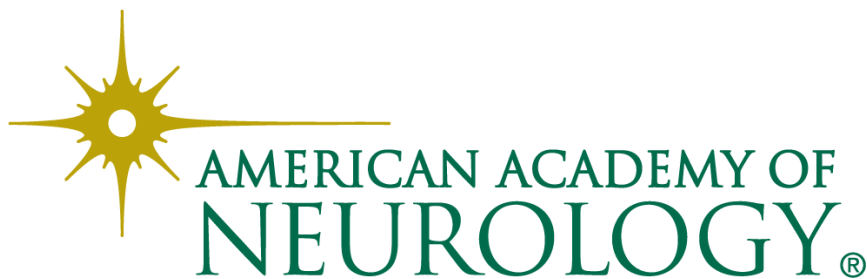

